\title{
À Espera da Reforma Orçamentária: Um Mecanismo Temporário para Redução de Gastos Públicos
}

\author{
Carla G. Protásio \\ Analista de Controle Externo do Tribunal de Contas da União \\ Maurício S. Bugarin \\ Professor do Departamento de Economia, Universidade de Brasília \\ Mirta N. Sataka Bugarin \\ Professora do Departamento de Economia, \\ Universidade de Brasília
}

\section{RESUMO}

Este trabalho evidencia distorções associadas à prática comum de contingenciamento do orçamento público federal e sugere um mecanismo alternativo de aplicação temporária que reduz essas distorções. Após verificar a evidência empírica de que há grande variação na execução orçamentária, com elevada concentração de gastos no último mês do exercício fiscal, constrói-se um modelo do tipo Principal-Agente que evidencia a ineficiência existente no processo orçamentário atual. Em seguida é apresentado um modelo alternativo Pareto superior que reduz a variação dos recursos disponíveis aos órgãos da administração pública ao longo do ano e ao mesmo tempo induz uma redução espontânea de seus gastos. Para ilustrar os ganhos potenciais da aplicação de tal mecanismo, apresenta-se uma simulação baseada da execução orçamentária de 2001 .

\section{PALAVRAS-CHAVE}

orçamento público, gasto público, desenho de mecanismos, incentivos

\section{ABSTRACT}

The present paper introduces a mechanism aimed at controlling a practice commonly adopted by many government agencies which consists of spending the entire budget by the end of each fiscal year in order to avoid cuts in the following year's budget allocation. As a result of the proposed incentive-mechanism, the government will be able to induce a voluntary reduction in the agencies' expenditure. Consequently, the central government will not need to resort to "fiscal repression", a mechanism used to control agencies' expenditures, which causes many distortions in the public sector. A simulation based on data from fiscal year $200 \mathrm{I}$ in Brazil illustrates the potential expenditure reduction when such mechanism is adopted.

KEY WORDS public budget, public expenditure, mechanism design, incentives

JEL Classification

D78, $\mathrm{H} 30, \mathrm{H} 6 \mathrm{I}$ 


\section{INTRODUÇÃO}

Após a queda da inflação obtida no Brasil com o Plano Real, a década de 90 foi marcada pela preocupação com a dívida pública, pelos elevados déficits e por medidas de ajuste fiscal. Em 1998, o País adotou o Programa de Estabilidade Fiscal e firmou acordo com o FMI, comprometendo-se com rígidas metas de superávit primário. Desde então, o processo de ajuste tem sido bem-sucedido. No entanto, subsiste a preocupação com a possibilidade de sustentabilidade da política fiscal, uma vez que o ajuste foi, em grande parte, baseado em medidas temporárias de aumento da receita. Além disso, o esforço de diminuição de gastos tem encontrado obstáculos na elaboração e execução orçamentárias.

O orçamento brasileiro é elaborado com base nos valores da execução da despesa dos últimos três anos. Essa metodologia induz os órgãos a gastarem todos os recursos disponíveis, muitas vezes em gastos não essenciais, receando um corte em orçamentos futuros.

Por sua vez, os mecanismos utilizados pelo governo para diminuir os gastos têm sido o contingenciamento e o controle das liberações de recursos financeiros pelo Tesouro Nacional. Esses instrumentos, no entanto, tendem a gerar uma série de distorções no gasto público, além de perderem eficácia com o fim da inflação elevada: em regime de baixa inflação, recursos represados ao longo do ano, mas liberados no final do exercício, representam limitada economia para os cofres públicos.

Considerando esse contexto, o presente trabalho propóe um modelo temporário de incentivos para que os órgãos diminuam voluntariamente seus gastos, enquanto não se alcança a elaboração de orçamento mais realista. $\mathrm{O}$ mecanismo proposto, se otimamente implementado, implica uma redução dos gastos mais adequada às verdadeiras prioridades e metas do governo, contribuindo para o ajuste fiscal e para a qualidade do gasto público.

Na próxima seção é feita uma breve descrição do ajuste fiscal adotado, com ênfase no papel do orçamento nesse processo. A seção 2 apresenta uma 
análise econométrica dos dados disponíveis, que evidencia a existência de um viés de grande aumento de gastos públicos no último mês do exercício fiscal. A terceira seção mostra, por meio de um modelo Principal-Agente estático, que o mecanismo de contingenciamento utilizado atualmente para o controle dos gastos públicos tem limitado efeito em período de baixa inflação e gera ineficiência na ordenação temporal da execução orçamentária. A seção 4 mostra que as características evidenciadas no modelo estático se reproduzem num modelo dinâmico envolvendo dois exercícios orçamentários consecutivos. A quinta seção propõe o mecanismo de redução voluntária de gastos e mostra seus efeitos positivos tanto no ajuste fiscal quanto na redução da ineficiência temporal da execução orçamentária. A seção 6 ilustra os ganhos potenciais associados a esse mecanismo a partir de uma simulação baseada em dados de 2001. Finalmente, a última seção apresenta algumas considerações finais sobre o modelo estudado.

\section{A EXECUÇÃO ORÇAMENTÁRIA EM TEMPO DE AJUSTE FISCAL}

Nos últimos vinte anos a economia brasileira tem passado por uma grave crise fiscal. Entre suas causas destacam-se os ajustamentos externos aos choques do petróleo e à crise dos juros no fim da década de 70; a queda da receita tributária bruta, causada pelo efeito Tanzi ${ }^{1}$ e pelo baixo crescimento econômico; o aumento das despesas com pessoal na primeira metade da década de 80; e os mecanismos de financiamento da dívida pública centrados na emissão de títulos e de base monetária, causando aumento da inflação e das despesas com juros. A Constituição Federal de 1988, que aumentou a transferência de impostos para Estados e municípios sem que houvesse uma

1 O Efeito Tanzi reduz o valor real dos impostos devido à inflação existente no lapso de tempo entre o fato gerador do imposto e seu recolhimento (vide TANZI, 1977). Deve-se notar, no entanto, que no caso do Brasil esse efeito foi reduzido devido à sofisticação do sistema de indexação dos tributos, como a UFIR, que chegou a ser atualizada diariamente entre o final de 1989 e o início de 1990. Vide, a esse respeito, REZENDE (2001) ou GIAMBIAGI \& ALÉM (2001). 
redistribuição das despesas, ${ }^{2}$ tornou-se um fator a mais para o agravamento da situação fiscal.

O fracasso dos planos heterodoxos de combate à inflação fez com que se generalizasse no meio político e acadêmico a convicção de que um ajuste fiscal era necessário para resolver o problema da alta inflação. Um tal ajuste diminuiria a participação do governo na demanda agregada, o que compensaria a pressão inflacionária gerada pelo aumento do consumo privado numa tentativa de desindexação da economia. Assim, a partir de 1990 iniciaram-se medidas para controle do déficit. Até 1993, verificaram-se melhoras causadas por medidas temporárias de aumento da receita e por mudanças estruturais, como a privatização, o controle do endividamento dos Estados da federação e o programa de combate às fraudes na Previdência Social.

A partir de 1995, com o Plano Real, a inflação caiu drasticamente e as contas públicas entraram em elevado desequilíbrio. Passou-se de superávit primário $^{3}$ de 5,21\% do PIB, em 1994, para déficit de 0,879\% do PIB em 1997, apesar do aumento da receita líquida do Tesouro. Em parte, esse desequilíbrio pode ser explicado pelo fato de que antes de 1995 a elevada inflação não fazia com que os déficits se concretizassem. $\mathrm{O}$ valor das dotações orçamentárias era corroído pela inflação, já que essas eram executadas, em sua maior parte, nos últimos meses do ano devido ao uso dos contingenciamentos e da postergação das liberações financeiras pelo Tesouro Nacional. Dessa forma, a inflação prejudicava a percepção do grave desequilíbrio que já existia entre receitas e despesas. Concomitantemente, houve piora do resultado previdenciário e aumento dos gastos com custeio.

2 A Constituição Federal de 1988 assegurou 44\% da arrecadação do Imposto de Renda e do Imposto sobre Produtos Industrializados (IPI) para os Fundos de Participação dos Estados e Municípios, 3\% desses impostos para fundos de desenvolvimento regionais e $10 \%$ da arrecadação do IPI para os Estados exportadores. Os municípios ainda foram contemplados com $50 \%$ da arrecadação do Imposto sobre Propriedade Territorial e com a totalidade da arrecadação do Imposto sobre Operações Financeiras incidente sobre o ouro, quando definido em lei como ativo financeiro. Em relação à competência tributária, a União eliminou seus impostos únicos. Esses foram incorporados à base de cálculo do ICMS, um imposto estadual.

3 De acordo com a Necessidade de Financiamento do Setor Público (NFSP-conceito primário, Banco Central do Brasil), obtido en IPEADATA, http://www.ipeadata.gov.br. 
Entre 97 e 98, as crises asiática e russa fizeram com que os juros fossem elevados para deter a fuga de capitais, pressionando o déficit público e colocando em jogo a credibilidade da economia brasileira. Com a consciência da urgente necessidade de saneamento das finanças públicas, em 1998 foi adotado o Programa de Estabilidade Fiscal (PEF) e firmado um acordo com o FMI. Fixaram-se metas de superávit primário para os anos de 1999 a 2001 com o objetivo de estabilizar a relação dívida/PIB.

O esforço tem sido significativo, e um severo processo de ajustamento ocorreu. ${ }^{4}$ A queda da despesa ocorrida entre 1998 e 2001 é mostrada na Tabela 1. O impacto do PEF sobre a receita, em 1999, foi de R \$ 24,1 bilhões e a receita total aumentou $0,5 \%$ do PIB. Por sua vez, o resultado primário registrou valor superior ao critério de desempenho acordado: obteve-se superávit de R \$ 31,1 bilhões, quando a meta estabelecida era de R \$ 30,2 bilhões. (SPE/MF, 2000).

TABELA I - DESPESAS DO GOVERNO CENTRAL/PIB (\%)

\begin{tabular}{lrrrrr}
\hline DISCRIMINAÇÃO & 1998 & 1999 & 2000 & 2001 & 2002 \\
\hline DESPESA TOTAL & 19,8 & 18,7 & 16,1 & 17,1 & 17,7 \\
Estados e Municípios & 3,0 & 3,2 & 3,7 & 3,8 & 4,2 \\
Benefícios & 5,9 & 5,8 & 6,1 & 6,3 & 6,6 \\
Adm. Federal & 10,5 & 9,5 & 10 & 10,8 & 11 \\
$\quad$ - Pessoal & 5,1 & 4,9 & 5,1 & 5,4 & 5,5 \\
- Custeio & 5,4 & 4,6 & 4,9 & 5,4 & 5,5 \\
Subsídios & 0,3 & 0,3 & 0,3 & 0,4 & 0,2 \\
\hline
\end{tabular}

Fonte: STN, Resultado do Tesouro Nacional-dez/1999 a dez/2002.

As metas estabelecidas têm sido cumpridas. No entanto, o principal questionamento que subsiste diz respeito à possibilidade de sustentabilidade do ajuste fiscal ao longo do tempo, uma vez que grande parte do Programa foi baseada em medidas temporárias de aumento da receita, como, por exemplo,

4 Vale observar que apesar desse relativo sucesso, a razão dívida líquida/PIB não se estabilizou, passando de 32,6\% em janeiro de 1994 para 52,4\% em janeiro de 2000. Para uma análise dos motivos desse aumento, vide OURIVES (2002) ou SIGELMANN (2002). 
a cobrança da CPMF e a receita de concessões de serviços de telefonia. ${ }^{5} \mathrm{~A}$ Tabela 2 mostra o peso das receitas extraordinárias no processo recente de ajuste fiscal, que chegaram a representar 3,2\% do PIB brasileiro em 1999, mas que deverão desaparecer nos próximos anos. Aumentar a carga tributária para compensar essa redução de receitas não seria compatível com os objetivos de crescimento, uma vez que essa carga já se encontra em torno de $30 \%$ do PIB. Assim, ainda há a necessidade de reduzir gastos para a sustentabilidade da política fiscal e reforço da credibilidade na economia brasileira.

\begin{tabular}{|c|c|c|c|}
\hline Composição & 1998 & 1999 & 2000 \\
\hline \multirow[t]{2}{*}{ CPMF } & 0,9 & 0,9 & 1,6 \\
\hline & 1,0 & 1,0 & 0,5 \\
\hline IR Excedente & 0,1 & 0,1 & 0,1 \\
\hline \multirow{2}{*}{ IR Bens Financeiros } & 0,3 & 0,0 & 0,0 \\
\hline & 0,0 & 0,3 & 0,3 \\
\hline \multirow[t]{2}{*}{ FEF/DRU } & 0,3 & 0,3 & 0,1 \\
\hline & 0,0 & 0,6 & 0,0 \\
\hline TOTAL & 2,6 & 3,2 & 2,6 \\
\hline
\end{tabular}

Fonte: AVERBUG \& GIAMBIAGi (2000).

Um importante mecanismo que tem sido utilizado para conter gastos é a repressão fiscal por meio do contingenciamento de créditos orçamentários e do controle das liberações financeiras pelo Tesouro Nacional.

Vale destacar que contingenciamento é um corte nas dotações orçamentárias dos diversos órgãos. Em geral, parte do contingenciamento efetuado logo após a aprovação do orçamento é mantida até o fim do exercício, configurando-se em perda de orçamento para o órgão. Mas parte desse corte orçamentário acaba sendo descontingenciada ao longo do período, à medida que os órgãos competentes (Ministérios da Fazenda e Planejamento) acompanham a arrecadação e o atendimento das metas de superávit primário

5 Vide, a esse respeito, GIAMBIAGI \& RIGOLON (1999). 
e cedem à pressão de gastos dos órgãos. O modelo aqui proposto aplica-se a essa parte dos créditos que acaba sendo descontingenciada e à postergação das liberações financeiras efetuadas pelo Tesouro Nacional. Portanto, este estudo não analisa os efeitos macroeconômicos das distorções associadas aos montantes contingenciados que nunca retornam aos órgãos.

O instrumento do contingenciamento utilizado para conter os gastos dos órgãos, ${ }^{6}$ gera uma série de distorções, como a inversão de prioridades, segundo a qual os órgãos gastam primeiramente em ações menos prioritárias para forçar a liberação de recursos para ações que não podem ser adiadas, e o endividamento por meio de atrasados, que faz com que os fornecedores cobrem do governo preços acima daqueles vigentes no mercado. Além disso, com o fim da inflação elevada, esses mecanismos perderam eficácia, pois as dotações orçamentárias não têm mais seu valor tão fortemente corroído. Dessa forma, é necessário um orçamento realista, com despesas compatíveis com o nível de receitas e com prioridades e metas bem especificadas. O Brasil tem caminhado nesse sentido com reformulações nas técnicas de planejamento e orçamentária. Além de procurar uma previsão de receita cada vez mais acurada e de compatibilizar as despesas com esses recursos, o objetivo tem sido definir precisamente as prioridades da sociedade, estabelecer metas físicas nos planos e enfatizar o acompanhamento da consecução dos programas. Tais objetivos almejam os resultados e os alcances de metas obtidos e não apenas a conformidade legal e contábil da execução orçamentária. ${ }^{7}$

No entanto, há ainda muito a ser feito, uma vez que o orçamento das unidades da administração pública ainda é definido com base na execução da despesa nos últimos três anos. Este aspecto da elaboração do orçamento faz com que os órgãos adotem o chamado "comportamento incremental",

6 É importante notar que, havendo incerteza acerca de qual será a receita efetiva ao longo do ano, pode ser natural algum nível de contingenciamento nos primeiros meses, seguido de descontingenciamento à medida que a receita vai ser materializando. Agradecemos a um parecerista anônimo por esta importante observação. No entanto, a evidência apresentada neste estudo sugere que $o$ mecanismo do contingenciamento tende a ser usado muito mais acentuadamente do que seria ótimo se a preocupação do governo consistisse apenas do equilíbrio entre receita (estocástica) e despesa.

7 Esses objetivos foram enfatizados principalmente com o Plano Plurianual para o período de 2000 a 2003 e seguiram as orientações do Decreto 2.829 de 28 de outubro de 1998 e da Portaria no 42 de abril de 1999, da Secretaria de Orçamento Federal. 
segundo o qual a dotação orçamentária da unidade é muitas vezes executada em sua totalidade, mesmo que não seja em gastos prioritários, para evitar que orçamentos futuros sofram reduções. Esse comportamento induz a que permaneçam na proposta orçamentária dos órgãos ações não prioritárias ou então projetos e atividades com valores acima das reais necessidades. Essa prática é contrária aos objetivos de política fiscal e prejudica os fundamentos e as técnicas de bom planejamento e orçamento que têm sido perseguidas. O gráfico referente à execução mensal da despesa em custeio, investimento e inversões financeiras evidencia o comportamento incremental dos órgãos e o uso do contingenciamento e do controle das liberações de recursos financeiros. Verifica-se, por meio dele, que a maior parte da despesa é executada nos últimos meses do ano, sendo que no mês de dezembro ocorre um salto muito significativo dos valores observados.

\section{GRÁFICO 1 - EXECUÇÃO MENSAL DA DESPESA EM CUSTEIO, IN- VESTIMENTO E INVERSÕES FINANCEIRAS (1996 - 2001)}

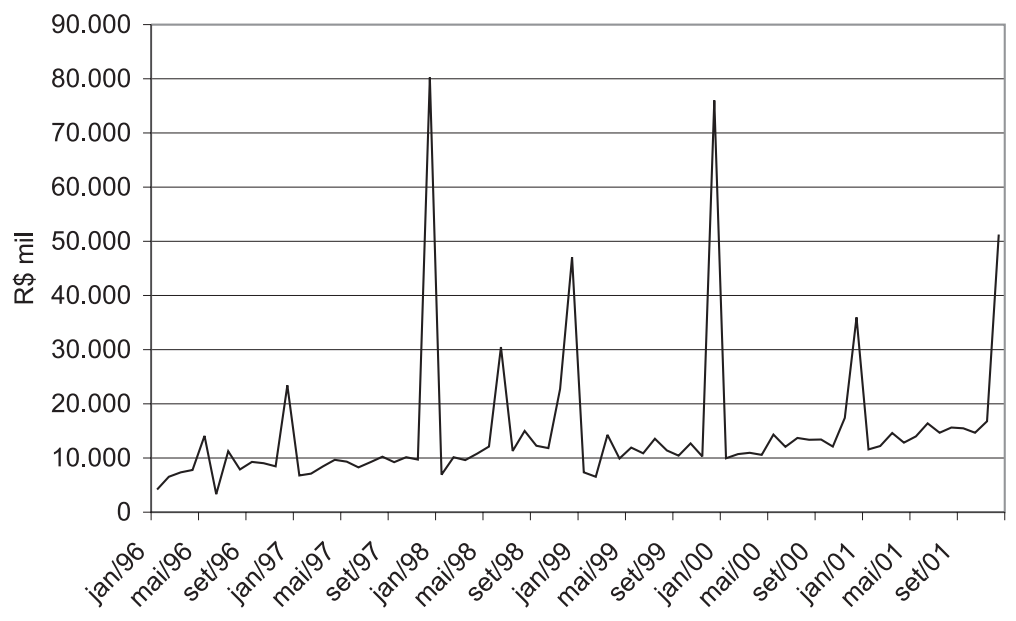

Fonte: SIAFI, Secretaria do Tesouro Nacional, STN/MF.

A próxima seção apresenta um estudo econométrico que corrobora a evidência apresentada no gráfico acima. 


\section{EVIDÊANCIAS EMPÍRICAS}

Esta seção destina-se a descrever, mediante o instrumental econométrico, os fatos estilizados que caracterizam o comportamento da execução orçamentária dos órgãos governamentais. De posse dessa caracterização, poder-se-á sustentar um modelo alternativo que considera o papel fundamental dos incentivos para obter uma alocação mais eficiente dos recursos públicos.

\subsection{Modelo Econométrico}

O objetivo do presente estudo econométrico é inferir relações estatisticamente significativas no que diz respeito à periodicidade na execução orçamentária dos órgãos governamentais. A hipótese fundamental refere-se à existência de um comportamento diferenciado na execução orçamentária no mês de dezembro de cada ano, bem como uma relação da execução orçamentária corrente com a mesma variável defasada $n$ períodos, $G_{t}=f\left(G_{t-n}\right)$, em que as defasagens consideradas são $n=6$ ou alternativamente $n=12$. A escolha dessas defasagens, por sua vez, justifica-se pela evidência apresentada no Gráfico 1. Os dados utilizados constam da Execução Mensal da Despesa em Custeio e Investimento e Inversões Financeiras obtidos no SIAFI/STN do período janeiro de 1996 a dezembro de 2001.

Primeiramente, o teste ADF foi realizado sobre a série de despesa executada para testar a hipótese nula de raiz unitária, com o objetivo de verificar a estacionariedade da série sob análise. A equação estimada considerou tanto um termo constante quanto uma tendência, pois a série original apresenta uma leve tendência. ${ }^{8} \mathrm{~A}$ hipótese nula foi rejeitada contra a alternativa (one-sided) a um nível de significância de $1 \%$, conforme o valor crítico de MacKinnon ${ }^{9}$ para rejeição da hipótese de raiz unitária.

8 Ver HAMILTON (1994).

9 Ver MACKINNON (1991). 
Uma vez estatisticamente verificada a estacionariedade da série, várias especificações alternativas do modelo reduzido foram testadas. A seleção da melhor especificação baseou-se nos critérios de Akaike e Schwarz. Considerando que a diferença entre os dois critérios reside basicamente no fato do segundo prejudicar mais fortemente o número de variáveis explicativas consideradas no modelo reduzido, optou-se por escolher o modelo de acordo com o primeiro critério de seleção.

Conforme a regra adotada de seleção, o modelo reduzido abaixo foi escolhido:

$$
\log \left(G_{t}\right)=a_{0}+a_{1} D+a_{2} \log \left(G_{t-12}\right)+\varepsilon_{t}
$$

Esta especificação denota uma relação log-linear entre execução orçamentária em um determinado mês e aquela executada 12 meses antes. A variável $D$ denota uma dummy que adquire, por construção, um valor igual à unidade no mês de dezembro e zero para os outros meses do ano. Esta última variável foi introduzida com o intuito de capturar os picos presentes nos dados nesse mês da amostra considerada. Em outras palavras, se de forma estatisticamente significativa existir a primeira relação, o coeficiente da dummy poderá avaliar se a mesma fica magnificada no mês de dezembro da amostra. Finalmente, a variável $\varepsilon_{t}$ denota a realização de uma variável aleatória de um processo estocástico ruído branco, com média zero e variância constante.

\subsection{Resultados Obtidos}

A Tabela 3 , a seguir, relaciona os resultados econométricos obtidos mediante a estimação do modelo log-linear (1), escolhido pelo critério de Akaike.

O método de mínimos quadrados ordinários foi utilizado, constatando-se que a especificação escolhida descreve, de forma estatisticamente significativa, os dados da amostra. Em particular, o estatístico Prob(F-stat) $=0.0000$, que capta o nível de significância marginal do teste $\mathrm{F}$, permite rejeitar a hipótese nula de coeficiente (de inclinação) igual a zero. 
O estatístico Durbin-Watson apresentou-se um pouco inferior a 2, indicando a possibilidade de uma correlação serial positiva dos resíduos. No entanto, o Teste de Breusch-Godfrey implementado mostrou que o estatístico associado ao teste de máximo-verossimilhança apresta probabilidades efetivamente superiores a zero $(0,85)$ de ausência de correlação serial nos resíduos estimados.

TABELA 3 - Modelo: $\log \left(G_{t}\right)=a_{0}+a_{1} D+a_{2} \log \left(G_{t-12}\right)+\varepsilon_{t}$ Número de Observaçôes: 60

\begin{tabular}{lccrc}
\hline Variável & Coeficiente & Desvio Padrão & Estatístico t & Probabilidade \\
\hline Constante & 13,00994 & 1,643822 & 7,91445 & 0,0000 \\
Dummy $(\mathrm{D})$ & 1,252819 & 0,204445 & 6,127889 & 0,0000 \\
Despesas $\left(\mathrm{G}_{\mathrm{t}-12}\right)$ & 0,201979 & 0,101807 & 1,983940 & 0,0521 \\
\hline \multicolumn{5}{c}{} \\
\\
& R-quadrado: 0,716758 & \\
& R-quadrado Ajustado: 0,706820 & \\
& Estatístico Durbin-Watson: 1,879318 & \\
& Estatístico F: 72,12076 & \\
& Prob(Estatístico $\mathrm{F}): 0,00000$ & \\
\hline
\end{tabular}

Em relação aos coeficientes individuais, podemos observar, a um nível de significância de até $5 \%$, que o logaritmo do orçamento executado corrente possui uma elasticidade de aproximadamente $10 \%$ em relação ao mesmo gasto realizado 12 meses atrás. Em outras palavras, um aumento de 1\% deste último acarreta um aumento de $10 \%$ no orçamento executado corrente. Além disso, o coeficiente estatisticamente significativo e positivo do coeficiente associado à dummy indica, por sua vez, que essa mesma elevada correlação positiva fica efetivamente mais acentuada no mês de dezembro dentro da amostra considerada. Trata-se, pois, da evidência econométrica do "comportamento incremental" segundo o qual existe um aumento significativo na execução orçamentária no último mês do ano.

Tendo em vista o incentivo adverso causado pelo processo orçamentário evidenciado acima, este trabalho propõe um mecanismo temporário para induzir uma redução voluntária de gastos por parte dos órgãos da administração pública. O objetivo é eliminar o comportamento incremental dos órgãos, possibilitando a redução do uso do contingenciamento e do controle 
das liberações financeiras. Com a adoção do modelo, é possível gerar ganhos para órgãos e para a política fiscal, uma vez que os gastos são diminuídos e executados de forma mais planejada, de acordo com as verdadeiras prioridades do órgão, da sociedade e da política econômica. Na próxima seção a situação atual é analisada sob a ótica de um modelo Principal-Agente, evidenciando a perda de eficiência ocasionada pelo contigenciamento.

\section{INCENTIVOS NA EXECUÇÃOO ORÇAMENTÁRIA: A SITU- $A C ̧ \tilde{A} O A T U A L$}

Nesta seção são analisados os incentivos com os quais se defrontam atualmente os órgãos públicos, no que diz respeito à política de gastos, e o governo central, no que se refere ao contingenciamento dos recursos a serem repassados aos órgãos da administração pública federal.

\subsection{O Modelo Básico}

O relacionamento entre o governo e seus órgãos pode ser caracterizado por meio de um modelo do tipo Principal-Agente, onde o Principal é representado pelo governo, mais especificamente pelos órgãos que têm a função de agir para a obtenção de superávits primários (no Brasil, os Ministérios da Fazenda e do Planejamento). Os agentes são os diversos órgãos que recebem dotações orçamentárias para serem executadas. O principal tem o objetivo de obter resultados primários positivos para a sustentabilidade do ajuste fiscal. Para isso, muito contribui a diminuição do gasto público. Por sua vez, os agentes devem decidir como gastar sua dotação orçamentária de forma ótima.

No presente modelo supóe-se, por simplicidade, que o orçamento anual de um órgão, $B$, será gasto em dois períodos, 1 e 2 . Então, $b_{1}+b_{2}=B$, onde $b_{k}$ é a parte o orçamento gasto no período $k, k=1,2$. O órgão deriva utilidade $U\left(b_{k}\right)$ do uso da dotação $b_{k}$ no período $k$. Não se considera desconto intertemporal no mesmo ano, de forma que a utilidade do órgão no ano é $U\left(b_{1}\right)+U\left(b_{2}\right)$. O órgão é estritamente avesso ao risco, sendo sua utilidade 
duas vezes diferenciável, estritamente crescente e estritamente côncava: $U^{\prime}>0$ e $U^{\prime \prime}<0$.

Se o órgão pudesse decidir como alocar os recursos livremente em cada período do ano, seu problema de maximização seria:

$$
\left\{\begin{array}{r}
\underset{b_{1}, b_{2}}{\operatorname{Max}} U\left(b_{1}\right)+U\left(b_{2}\right) \\
\text { r.a.: } b_{1}+b_{2} \leq B
\end{array}\right.
$$

Observe que a modelagem usada supõe que a utilidade do órgão é aditivamente separável nos diferentes períodos. Trata-se de uma hipótese essencialmente técnica que facilita muitíssimo a análise do problema. Para uma discussão sobre essa hipótese vide, por exemplo, Blanchard e Fischer (1992, p. 69).

A solução do problema de maximização acima é $b_{1}=b_{2}=\frac{B}{2}$. Assim, na ausência de restrições ao uso de sua dotação, o órgão maximiza sua funçãoobjetivo dividindo seu orçamento igualmente entre os dois períodos. Este resultado se estende imediatamente para qualquer número de períodos, em particular doze, correspondendo aos doze meses do ano. Destarte, a solução ótima para o órgão é executar um doze avos de seu orçamento a cada mês do ano. A concentração da execução nos últimos meses do ano, gerada pelo comportamento incremental e pela repressão fiscal, faz com que o nível de utilidade obtido pelo órgão seja menor.

\section{Exemplo}

O resultado acima pode ser ilustrado com os dados de execução do Ministério da Educação do Brasil em reais, em 2001. A despesa executada entre janeiro e junho foi $b_{1}=2.728 .231,28$ mil reais e a executada entre julho e dezembro, $b_{2}=7.027 .497,74$ mil reais, perfazendo um total de $B=\mathrm{R} \$$ 9.755.729,02 mil no ano. Se dividido em duas parcelas iguais, ter-se-ia: $B / 2$ $=4.877 .864,51$ mil reais. Supondo que a função de utilidade seja: $U(x)=$ $\log (x)$, em que $x$ corresponde ao gasto efetuado pelo órgão em bilhões de reais, a utilidade do órgão no ano foi: $U=\log (2,728231)+\log (7,027497)=2,9535$. 
Se o órgão pudesse executar metade da sua despesa a cada período, sua utilidade seria: $U^{*}=2 \times \log (4,877864)=3,1694$. Note que $U<U^{*}$, o que representa uma perda de utilidade da ordem de $7,31 \%$ na situação atual.

\subsection{Incorporando o Contingenciamento e a Existência da Inflação}

Conforme ressaltado anteriormente, o governo brasileiro vem usando a repressão fiscal para postergar a execução orçamentária e diminuir o gasto público. Nesta subseção, incorpora-se a inflação ao modelo para mostrar como o uso desse mecanismo gera pequenos ganhos num ambiente de preços relativamente estáveis.

Suponha que o governo libere $b_{1}$ no primeiro período e que $b_{1}<\frac{B}{2}$. Ele pode aplicar a diferença e receber, aproximadamente, $(1+i)\left(\frac{B}{2}-b_{1}\right)^{2}$ no segundo período, em que $i$ é a taxa SELIC verificada no primeiro período, obtendo um ganho líquido de $i\left(\frac{B}{2}-b_{1}\right)$. O uso da SELIC para obter a economia do governo se justifica pelo fato dessa taxa ser o custo implícito na emissão de títulos, já que o objetivo da economia de recursos é, em última instância, diminuir o déficit e a necessidade de emissão de títulos.

Para construir o problema de maximização do governo, suponha que $\bar{b}<\frac{B}{2}$ é o nível mínimo de gasto que pode ser atribuído ao órgão em cada período. Isto significa que a execução orçamentária do órgão em cada período não pode ser inferior a $\bar{b}$. Esta hipótese pode ser justificada de várias formas: o gasto pode ser o gasto mínimo de funcionamento, referindo-se, por exemplo, ao pagamento de pessoal e custos básicos fixos de manutenção do órgão; pode também existir um componente político que impede a redução de ou até mesmo uma restrição constitucional que requer certo repasse de recursos para o órgão.

Assim, o problema do governo pode ser escrito como: 


$$
\left\{\begin{array}{c}
\underset{b_{1}, b_{2}}{\operatorname{Max}} i\left(\frac{B}{2}-b_{1}\right) \\
r . a: b_{1}+b_{2}=B \\
b_{1} \geq \bar{b}
\end{array}\right.
$$

A solução desse problema é imediata: $b_{1}=\bar{b}$ e $b_{2}=B-\bar{b}$. Portanto, o melhor para o governo é contingenciar ao máximo. O ganho financeiro, para o governo, com o uso dessa prática é: $G=i\left(\frac{B}{2}-\bar{b}\right)$. A conseqüência para o órgão é uma perda de utilidade $\Delta U=2 U\left(\frac{B}{2}\right)-U(\bar{b})-U(B-\bar{b})$, se comparada com a situação de gastos iguais nos dois períodos.

\section{Exemplo}

Continuando o exemplo com dados do Ministério da Educação em 2001 e com valores da SELIC entre janeiro e junho de 2001 ( $\left.i_{1}=7,78 \%\right)$, o ganho financeiro do governo seria: $G=194.616,80$ mil reais, ${ }^{10}$ mas resultando numa perda de utilidade para o órgão de $7,31 \%$, conforme visto anteriormente.

Apesar desse resultado negativo para o órgão, conclui-se que o melhor para a concretização do objetivo do governo é contingenciar o máximo possível. Da forma como o orçamento é elaborado e executado, o governo não tem incentivos para reduzir o uso da repressão fiscal. Sem ela, os órgãos continuariam a gastar todo o orçamento, mesmo que não fosse necessário para garantir suas dotações futuras, e o governo não teria economia alguma de recursos. Vale ressaltar a dependência do governo em relação à SELIC e, consequientemente, à taxa de inflação. Quanto menor for $i$, menor será o ganho do governo com a repressão fiscal e, conseqüentemente, mais estímulo o governo terá em contingenciar para compensar o baixo retorno $i$.

10 Observe também que no cálculo anterior o governo não considera diretamente a perda, para o órgão, associada ao contingenciamento. De fato, se essa perda fosse contabilizada, poder-se-ia chegar à conclusão que o custo social do contingenciamento não compensa o pequeno ganho, para o governo, quando a SELIC (e a inflação) não é significativa. 
Isto é o que tem sido observado nos últimos anos no Brasil: com a queda da inflação e o compromisso com a melhora da situação fiscal, maior tem sido o uso do contingenciamento. ${ }^{11}$

Para que os órgãos tenham incentivos a reduzir gastos, a estrutura do orçamento atual deve ser revista, principalmente o fato de o orçamento seguinte sofrer reduções se a execução da dotação disponível nos últimos três anos apresentar queda. Isso implicaria alteração de legislação e de normas dos órgãos envolvidos na elaboração e execução do orçamento.

Este trabalho propõe um mecanismo que incentiva a redução dos gastos não-prioritários que ocorrem com o comportamento incremental dos órgãos, possibilitando a redução gradual do contingenciamento. Na próxima seção, estende-se o modelo para um horizonte de dois anos, cada um dividido em dois períodos para, na seção seguinte, incluírem-se os incentivos para que os órgãos reduzam seus gastos no primeiro ano de forma a obter um orçamento mais flexível no ano seguinte. Mostra-se que tal mecanismo pode ser implementado com ganho efetivo tanto para o órgão quanto para o governo.

\section{O MODELO ESTENDIDO PARA DOIS ANOS CONSECUTIVOS}

Esta seção analisa os efeitos do contigenciamento tanto para o órgão que tem seus recursos contingenciados quanto para o governo federal, num contexto envolvendo dois exercícios fiscais consecutivos, cada um dividido em dois períodos.

11 Um contigenciamento crescente corresponderia a um valor de possivelmente variável no tempo, o que não é contemplado no presente modelo. No entanto, a Nota Técnica Conjunta COFF/ CONORF 08/2000 do Congresso ressalta que o valor contingenciado cresceu significativamente entre 1998 e 2000. Naquele ano, o valor cotingenciado foi de 16\%. Em 2000, passou-se para $19,9 \%$, apesar do aumento da arrecadação verificado e da melhora na forma de elaboração dos orçamentos. 


\subsection{Sem Contingenciamento: A Solução Ótima para o Órgão}

Considere, para efeito de comparação futura, que não há contingenciamento. O órgão dispõe de um orçamento $B_{1}$ a ser utilizado nos dois períodos do primeiro ano, e de um orçamento $B_{2}$ a ser gasto nos dois períodos do segundo ano. Seja $b_{i j}$ o montante utilizado no período $j$ do ano $i, i, j=1,2$. Então, $b_{11}+b_{12} \leq B_{1}$ e $b_{21}+b_{22} \leq B_{2}$. Se o órgão puder escolher, de forma ótima, como repartir seus gastos nos dois períodos, resolverá o seguinte programa.

$$
\left\{\begin{aligned}
\underset{b_{11}, b_{12}, b_{21}, b_{22}}{\operatorname{Max}} U\left(b_{11}\right)+U\left(b_{12}\right)+\delta\left[U\left(b_{21}\right)+U\left(b_{22}\right)\right] \\
r . a: \quad b_{11}+b_{12} \leq B_{1} \\
b_{21}+b_{22} \leq B_{2} \\
B_{2}=(1+\pi) f\left(b_{11}+b_{12}\right)
\end{aligned}\right.
$$

A primeira condição refere-se à restrição orçamentária do órgão no primeiro ano: o orçamento prevê o gasto (máximo) total de $B_{1}$ reais no primeiro ano, que será gasto em dois períodos 1 e 2: o primeiro e o segundo semestres. Já a segunda condição refere-se à restrição orçamentária no segundo período. O montante total disponível nesse período, $B_{2}$, depende de dois termos, expressos na última restrição. Em primeiro lugar, o montante nominal depende do gasto total executado no período anterior $b_{11}+b_{12}$; a função crescente $f$ reflete a propriedade, já citada, do processo orçamentário brasileiro: quanto menos se gasta num período, menor será o orçamento no período seguinte. Em segundo lugar, o orçamento no período 2 é corrigido pela taxa de inflação $\pi$ de forma a manter-se o mesmo valor real.

Supõe-se que $f\left(B_{1}\right)=B_{1}$, ou seja, o maior orçamento que o órgão pode garantir no ano seguinte $\left(B_{2}\right)$ é o orçamento atual $\left(B_{1}\right)$ corrigido pela inflação $(\pi)$. Isto também se justifica pelo objetivo de isolar o efeito do orçamento seguinte baseado na execução de despesa passada. O parâmetro $\delta$ é o fator de desconto entre os dois anos, ou seja, o custo implícito no uso do recurso apenas no segundo ano e não no primeiro. 
Solucionando esse problema, no primeiro ano, como a utilidade é estritamente crescente, quanto mais for gasto, melhor. Como $f$ é estritamente crescente, gastar tudo no primeiro ano é uma escolha ótima considerando também a consequiência no segundo período. Assim, $b_{11}+b_{12}=B_{1}$, $f\left(b_{11}+b_{12}\right)=f\left(B_{1}\right)=B_{1}$, e o problema torna-se equivalente a:

$$
\left\{\begin{array}{c}
\underset{b_{11}, b_{12}, b_{21}, b_{22}}{\operatorname{Max}} U\left(b_{11}\right)+U\left(b_{12}\right)+\delta\left[U\left(b_{21}\right)+U\left(b_{22}\right)\right] \\
r . a: \quad b_{11}+b_{12}=B_{1} \\
b_{21}+b_{22}=(1+\pi) B_{1}
\end{array}\right.
$$

Resolver o problema acima é equivalente a resolver dois problemas separadamente, um para cada ano. Assim, a solução desse problema corresponde a duas soluções sucessivas do problema para um período. Note que a solução para o segundo ano é igual à do primeiro, em termos reais: $b_{11}=b_{12}=\frac{B_{1}}{2}$ e $b_{21}=b_{22}=(1+\pi) \frac{B_{1}}{2}$.

O modelo confirma uma característica perversa do processo orçamentário atual, que induz o órgão a gastar o máximo, sem ter nenhum incentivo para a economia. Além disso, como no modelo estático (um ano), o ideal para o órgão é dividir igualmente seus gastos em cada período.

\subsection{Com Contingenciamento: A Solução Ótima Restrita para o Órgão}

Considere agora a situação mais próxima da realidade, em que o órgão não pode equilibrar os gastos, escolhendo o mesmo valor em cada período de um exercício, devido à existência de contingenciamento. Suponha que nos dois anos o governo escolhe o mesmo contingenciamento (em termos reais) $b$, em que $b \geq \bar{b}$ e $\bar{b}$ é o nível mínimo de gasto necessário para a manutenção do órgão. Logo, $b$ é o montante liberado pelo governo no primeiro período do primeiro ano, sendo $(1+\pi) b$ o montante correspondente liberado no primeiro período do segundo ano. Seja ainda $b_{i j}$ o montante utilizado no período $j$ do ano $i, i, j=1,2$. 
Assim, ${ }^{12} b_{11} \leq b<\frac{B_{1}}{2}$ e, no segundo ano, tem-se $b_{21} \leq(1+\pi) b<(1+\pi) \frac{B_{1}}{2}$.

Com isso, o órgão não pode adotar sua política ótima, $b_{11}=\frac{B_{1}}{2} \mathrm{e}$ $b_{21}=(1+\pi) \frac{B_{1}}{2}$, mas continuará gastando o máximo possível para assegurar o orçamento seguinte e aumentar sua utilidade atual, que é estritamente crescente. Assim, tem-se $b_{11}+b_{12}=B_{1}=: B$ e $B_{2}=(1+\pi) B$. Visando maximizar sua utilidade, o órgão escolherá o maior gasto possível em cada período contingenciado a fim de tornar o valor da despesa no primeiro período do ano o mais próximo possível do valor no segundo período, uniformizando ao máximo seu consumo. A solução do problema do órgão será: $b_{11}=b, b_{12}=B-b, b_{21}=(1+\pi) b$ e $b_{22}=(1+\pi)(B-b)$.

\subsection{Com Contingenciamento: O Contingenciamento Ótimo para o Governo}

Suponha agora que o governo queira decidir como determinar o nível de contingenciamento $b \geq \bar{b}$, de forma a maximizar seu próprio ganho com o mecanismo. Então, o objetivo do governo é maximizar a economia de recursos, e faz isso com a repressão fiscal, ganhando com a inflação. O problema do governo ${ }^{13}$ para dois anos é:

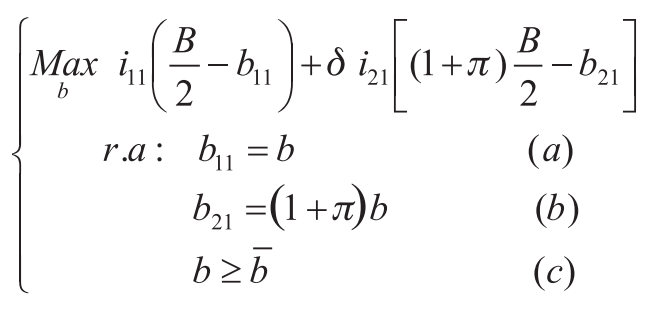

12 Observe que o governo poderia escolher contingenciar a um nível $b \geq B / 2$. Nesse caso, no entanto, o órgão gastaria apenas $B / 2$ e guardaria parte do orçamento para ser usado no segundo período. Em outras palavras, o contingenciamento seria uma restrição inativa. Essa escolha, no entanto, é dominada por um maior contingenciamento do ponto de vista dos objetivos do governo.

13 Vide no apêndice uma dedução cuidadosa da forma apresentada da função-objetivo do governo. 
Em que $(a)$ e $(b)$ representam a decisão que será tomada pelo agente uma vez definido o nível de contingenciamento $b$, ou seja, dado o nível de contingenciamento $b$ imposto pelo governo, o órgão gastará exatamente o montante máximo $b$ no primeiro período do primeiro ano e o montante máximo $(1+\pi) b$ no primeiro período do segundo ano. Em $(c), \bar{b}$ representa o nível mínimo de gasto necessário para a manutenção do órgão. Os parâmetros $i_{11} \mathrm{e} i_{21}$ representam as taxas SELIC correspondendo ao primeiro período do primeiro e do segundo ano, respectivamente. A função-objetivo do governo é calculada comparando-se o gasto que o governo teria caso não impusesse restrição aos gastos do órgão nos primeiros períodos de cada ano com o gasto que tem ao impor o contingenciamento; os detalhes do cálculo encontram-se no anexo deste trabalho.

Resolvendo o problema obtém-se $b=\bar{b}$, o que implica $b_{11}=\bar{b}, b_{12}=B-\bar{b}$ , $b_{21}=(1+\pi) \bar{b}$ e $b_{22}=(1+\pi)(B-\bar{b})$. Novamente repete-se a solução obtida para o modelo estático (um ano) no modelo dinâmico (dois anos). O ganho para o governo é:

$$
i_{11}\left[\frac{B}{2}-\bar{b}\right]+\delta i_{21}(1+\pi)\left[\frac{B}{2}-\bar{b}\right]=\left[i_{11}+\delta i_{21}(1+\pi)\right]\left[\frac{B}{2}-\bar{b}\right]
$$

Assim, quanto menores a taxa SELIC e a inflação, menor o ganho do governo. Observe ainda que, à medida que as limitações ao contingenciamento vão se ampliando - por meio de transferência obrigatórias por exemplo -, o valor de $\bar{b}$ vai aumentando, o governo tem menos flexibilidade para contingenciar e o seu ganho com esse mecanismo diminui ainda mais.

Como no modelo estático, conclui-se que os órgãos, dada a forma de elaboração do orçamento, não têm incentivos para economizar gastos. Por sua vez, o governo não tem incentivo para diminuir o contingenciamento. Na próxima seção sugere-se uma alteração do mecanismo atual, compatível com a nova realidade macroeconômica de inflação mais baixa e necessidade de diminuir despesas. São incluídos incentivos para que os órgãos não apresentem o comportamento incremental e gerem economia de recursos quando for possível. 


\section{DESENHO DE MECANISMOS NA EXECUÇÃOO ORÇA- MENTARIA: DOIS ANOS COM INCENTIVOS}

Os análises desenvolvidas nas seções 3 e 4 mostram que, com o objetivo de reduzir o custo financeiro do gasto público, o governo federal é levado a contingenciar ao máximo os recursos destinados aos órgãos nos primeiros meses do exercício fiscal, liberando mais recursos apenas nos últimos meses. Esse comportamento provoca grande variação nos valores disponíveis para os órgãos nos diferentes meses do ano, conforme evidenciado empiricamente na seção 2 e formalmente nas seções seguintes. Como os órgãos são avessos ao risco, essa variação nos montantes recebidos causa-lhes significativa perda de utilidade.

Por outro lado, num ambiente de controle macroeconômico o ganho para o governo com o contingenciamento torna-se cada vez menor à medida que a inflação e a taxa de juros na economia caem.

Destarte, o mecanismo atual é fonte de ineficiência ao impedir a equalização dos gastos dos órgãos ao longo do ano e traz reduzido benefício para o governo federal.

Diante dessa situação, surge naturalmente uma oportunidade estratégica da União induzir seus órgãos a reduzirem gastos de forma espontânea, desde que lhes ofereça em compensação uma redução na variação nos gastos nos períodos seguintes.

O mecanismo aqui proposto tem exatamente esse efeito. Em termos gerais, o mecanismo apresenta aos órgãos a possibilidade de receber no exercício seguinte uma proporção $\lambda \in(0,1]$ do valor de seu orçamento que foi economizado no exercício atual. Diante desta opção, e considerando que devido ao contingenciamento os recursos disponíveis no início do ano seguinte são sempre reduzidos, o órgão decidirá não gastar todo o orçamento disponível no final de um exercício, para poder transferir recursos para o início do exercício seguinte. Desta forma, o órgão terá uma distribuição mais equilibrada de recursos ao longo do tempo e a União terá um duplo benefício. Em primeiro lugar, induzirá a redução dos gastos num período 
e, em segundo lugar, parte dessa redução $(1-\lambda)$ poderá ser usada no abatimento efetivo da dívida pública, uma vez que não necessitará ser devolvida ao órgão. Portanto, o mecanismo distribui entre os órgãos (proporção $\lambda$ ) e a União (proporção $1-\lambda$ ) os benefícios resultantes da redução da variação nas execuções orçamentárias.

Ressalta-se, aqui, que a metodologia de definição dos limites orçamentários dos órgãos deve ser alterada, ou seja, os limites não devem ser diminuídos se a execução orçamentária dos três anos anteriores diminuir. Isso implicaria alteração de legislação e de normas institucionais dos órgãos envolvidos, o que pode dificultar a adoção do modelo sugerido, apesar de sua relativa simplicidade técnica. Supõe-se então que o orçamento seguinte é igual ao orçamento passado, corrigido pela taxa inflação verificada no período, mesmo que o órgão não gaste tudo. Desta forma, $B_{1}=B$ e $B_{2}=(1+r) B$.

Diante da oportunidade de receber parte de suas economias no período seguinte, o problema do órgão pode agora ser expresso como:

$$
\left\{\begin{aligned}
& \operatorname{Max}_{b_{11}, b_{12}, b_{21}, b_{22}} U\left(b_{11}\right)+U\left(b_{12}\right)+\delta\left[U\left(b_{21}\right)+U\left(b_{22}\right)\right] \\
& r . a: b_{11} \leq \bar{b} \\
& b_{11}+b_{12} \leq B \\
& b_{21} \leq(1+\pi) \bar{b}+\lambda\left[B-\left(b_{11}+b_{12}\right)\right] \\
& b_{21}+b_{22} \leq(1+\pi) B+\lambda\left[B-\left(b_{11}+b_{12}\right)\right]
\end{aligned}\right.
$$

Em que $\lambda \in(0,1]$ é o porcentual do total poupado no primeiro ano que será devolvido para o órgão no início do segundo ano. ${ }^{14} B$ é o orçamento básico no primeiro ano.

14 O modelo seria análogo se o governo corrigisse o valor da economia devolvida para o órgão pela taxa de inflação, como forma de compensar a perda de poder aquisitivo gerada pelo fato de economizar e não gastar os recursos no ano anterior. Neste caso, a segunda restrição do problema do governo seria substituída por: $b 21+b 22 \leq(1+\pi) B+(1+\pi) \lambda[B-(b 11+b 12)]$. Desta forma, o órgão teria um incentivo adicional a poupar, mas o governo reduziria seu ganho com a da economia induzida. 
A proposição a seguir apresenta a resolução desse problema.

\section{Proposição 1}

A solução do problema do órgão $\left(b_{11}, b_{12}, b_{21}, b_{22}\right)$ satisfaz: $b_{11}=\bar{b}$, $b_{21}=(1+\pi) \bar{b}+\lambda\left(B-\bar{b}-b_{12}\right)$ e $b_{22}=\left(1+\pi(B-\bar{b})\right.$, em que $b_{12}$ é a solução para a seguinte equação:

$$
U^{\prime}\left(b_{12}\right)=\delta \lambda U^{\prime}\left[(1+\pi) \bar{b}+\lambda\left(B-\bar{b}-b_{12}\right)\right]
$$

\section{Demonstração.}

Vide apêndice.

Com base na expressão acima pode-se enunciar a seguinte proposição.

\section{Proposição 2}

Se a taxa de inflação $\pi$ não for muito elevada, e o fator de desconto intertemporal do órgão $\delta$ for suficientemente próximo de um, então existirá um valor para o porcentual de restituição $\lambda \in(0,1]$ que induzirá o órgão a economizar um montante não nulo no segundo período do primeiro exercício fiscal.

\section{Demonstração.}

Observe que se $\delta=\lambda=1$ e $\pi=0$, a equação se reduz a:

$$
U^{\prime}\left(b_{12}\right)=U^{\prime}\left[\bar{b}+B-\bar{b}-b_{12}\right]=U^{\prime}\left(B-b_{12}\right)
$$

Como $U$ é estritamente côncava, conclui-se que $b_{12}=B-b_{12}$, o que implica a solução $b_{12}=\frac{B}{2}<B-\bar{b}$. Assim, quando $\delta=\lambda=1$ e $\pi=0$, o órgão economizará $B-\bar{b}-\frac{B}{2}=\frac{B}{2}-\bar{b}>0$ no primeiro ano. Destarte, por continuidade do problema de maximização nos parâmetros $\lambda$ e $\delta$, se $\lambda$ e $\delta$ forem suficientemente próximos de 1 e $\pi$ for suficientemente pequeno, então a solução 
$b_{12}$ é menor que $B-\bar{b}$ e o órgão decidirá economizar, o que é justamente o objetivo final deste mecanismo.

Note que o governo tem dois ganhos adicionais com esse mecanismo. Em primeiro lugar, a redução dos gastos do órgão no segundo período do primeiro ano implica uma economia, para a União, naquele período. Em segundo lugar, com esse mecanismo o governo recebe o valor de $(1-\lambda)\left(B-\bar{b}-b_{12}\right)>0$ , que pode ser usado para reduzir o principal da dívida pública.

Observe ainda que dos parâmetros $\lambda$ e $\delta$, um é escolhido pelo governo $(\lambda)$ e o outro é um dado da economia, tipicamente associado à taxa de inflação $(\delta)$. De fato, em equilíbrio têm-se $\delta=\frac{1}{1+r}$, em que $r$ é a taxa de juros real, dada pela diferença entre a taxa de juros nominal anual $i$ (SELIC) e a taxa de inflação $\pi: r=i-\pi$. Assim, se a taxa de juros real for muito elevada, então $\delta$ será bem pequeno e o órgão não terá incentivo em economizar, por maior que seja $\lambda$. Isto explica por que um mecanismo como este nunca foi considerado antes, no período de instabilidade econômica no Brasil.

Por outro lado, quanto menor for a taxa de juros real e, conseqüentemente, maior for $\delta$, mais baixo será o valor de $\lambda$ que o governo poderá escolher $\mathrm{e}$ que ainda estimulará a poupança por parte do órgão. Assim, um mecanismo como este se apresentará como extremamente oportuno no momento em que o País caminhar na direção de uma maior estabilidade macroeconômica associada a taxas de juros reais mais reduzidas. A União, por sua vez, determinará $\lambda$ de forma a maximizar seu retorno esperado com o mecanismo. Este retorno é dado pela expressão $G(\lambda)$ a seguir.

\section{Proposição 3}

O retorno adicional, para o governo federal, com mecanismo de incentivos $\lambda$ é dado pela função abaixo, em que o parâmetro $i_{j k}$ refere-se à taxa de juros (SELIC) correspondente ao período $k$ do exercício fiscal $j, j, k=1,2$. 


$$
\begin{aligned}
& G(\lambda)=i_{12}\left(B-\bar{b}-b_{12}\right)+\delta\left(1+i_{21}+i_{22}\right)(1-\lambda)\left(B-\bar{b}-b_{12}\right)= \\
& =\left[i_{12}+\delta\left(1+i_{21}+i_{22}\right)(1-\lambda)\right]\left(B-\bar{b}-b_{12}\right)
\end{aligned}
$$

\section{Demonstração}

Vide apêndice.

O primeiro termo da soma que caracteriza a função $G$ corresponde ao ganho da União no segundo período do primeiro exercício fiscal devido ao fato de que o montante $B-\bar{b}-b_{12}$ não se concretizará em termos de nova dívida nesse período. Alternativamente, pode-se dizer que nesse período o órgão deixa de gastar o montante $B-\bar{b}-b_{12}$, o que se reflete numa redução da dívida da União nesse valor nesse período, cujo custo é dado pela taxa de juros SELIC $i_{12}$. Por outro lado, a partir do primeiro período do exercício seguinte a União terá uma redução líquida da dívida pública no montante $(1-\lambda)\left(B-\bar{b}-b_{12}\right)$, cujo benefício encontra-se expresso no segundo termo da soma $(3)$.

Observe que o termo $b_{12}$ que aparece em (3) é, de fato, uma função do incentivo $\lambda: b_{12}=b_{12}(\lambda)$. Assim, o problema do governo reduz-se a escolher otimamente o nível de incentivo $\lambda$ de forma a maximizar a função retorno adicional $G(\lambda)$. Para resolver esse problema é necessário determinar o comportamento desta função $G(\lambda)$, o que é feito na próxima seção para o caso particular em que a função de utilidade do órgão assume a forma logarítmica.

\section{MECANISMO DE INCENTIVOS ÓTIMO}

Nesta seção particulariza-se novamente o modelo para a função $U(x)=\log (x)$, em que $x$ é medido em bilhões de reais. Substituindo em (2) obtém-se:

$$
\frac{1}{b_{12}}=\delta \lambda \frac{1}{(1+r) \bar{b}+\lambda\left(B-\bar{b}-b_{12}\right)}
$$

Donde, 


$$
b_{12}=b_{12}(\lambda)=\frac{(1+r) \bar{b}}{(1+\delta) \lambda}+\frac{B-\bar{b}}{1+\delta}
$$

Mas então,

$$
B-\bar{b}-b_{12}=\frac{\delta}{1+\delta}(B-\bar{b})-\frac{1+\pi}{1+\delta} \frac{\bar{b}}{\lambda}
$$

Substituindo a expressão acima em (3) obtém-se a economia adicional para o governo como função do incentivo $\lambda$ :

$$
G(\lambda)=\left[i_{12}+\delta\left(1+i_{21}+i_{22}\right)(1-\lambda)\right]\left[\frac{\delta}{1+\delta}(B-\bar{b})-\frac{1+\pi}{1+\delta} \frac{\bar{b}}{\lambda}\right]
$$

Observe que a função $G$ em (4) é duas vezes diferenciável para valores de $\lambda$ não nulos com $G^{\prime \prime}(\lambda)<0$. Assim, $G$ é estritamente côncava e a condição de primeira ordem (CPO) $G^{\prime}(\lambda)=0$ corresponde ao incentivo $\lambda$ que gera o maior retorno para o governo federal. A solução da CPO é dada por:

$$
\lambda=\sqrt{\frac{1+\pi}{\delta}\left(1+\frac{1}{\delta} \frac{i_{12}}{1+i_{21}+i_{22}}\right) \frac{\bar{b}}{B-\bar{b}}}
$$

A expressão (5) apresenta a escolha ótima de compartilhamento da economia efetuada no ano anterior, do ponto de vista do governo. Vale ressaltar que esse mesmo procedimento pode ser adotado para qualquer outra função estritamente côncava para se obter a relação entre $\lambda$ e $\delta$. Observe ainda que quanto maior for a taxa de inflação $\pi$ maior terá que ser o repasse a ser feito ao órgão para induzi-lo a reduzir seus gastos. Se $\pi$ for muito elevado, a solução $\lambda$ poderá ser maior que 1 : em regime de elevada inflação o órgão somente aceitaria reduzir seus gastos se recebesse uma quantia ainda maior que aquela poupada, como recompensa no período seguinte; isto mostra que um mecanismo desta natureza é dificilmente viável em ambiente de grande instabilidade macroeconômica.

\section{Simulação}

Considerando dados da execução da despesa dos anos de $2001,{ }^{15}$ pode-se 
fazer uma aplicação do modelo. Utiliza-se o valor da despesa total, ou seja, de todos os órgãos. Os dados dos doze meses são divididos em dois semestres. Portanto, a execução da despesa do primeiro semestre corresponde ao somatório da despesa executada entre os meses de janeiro e junho. Os dados do segundo semestre correspondem à soma entre julho e dezembro. O IPCA é o índice de preços utilizado para corrigir o orçamento do ano seguinte, já que é este o índice adotado para as metas de inflação fixadas pelo governo. No ano de 2001, este índice foi de $\pi=7,67 \%$.

Para o ano de 2001, tem-se, em milhões de reais, $B=210.066,30$, $b_{11}=81.662,77$ e $b_{12}=128.403,53$. Como não foi usado nenhum mecanismo de estímulo à redução de gastos supõe-se, de acordo com o presente modelo, que $\bar{b}=b_{11}=81.662,77$. A variação da taxa SELIC entre janeiro e junho de 2001 foi $i_{12}=7,78 \%$, sendo a variação da mesma taxa no ano de 2001 dada por $i=17,32 \%$. Ademais, a variação da taxa SELIC entre janeiro e junho de 2002 foi $i_{21}=8,67 \%$ e entre julho e dezembro de 2002 foi $i_{22}=9,66 \%$. Assim, $\delta=1 /(1+i-\pi)=0,912$. Para o ano 2002, supõe-se o mesmo contingenciamento para simplificar os cálculos, sendo o orçamento corrigido pela inflação $\pi$.

Portanto, na situação atual sem incentivos ter-se-ia $b_{12}=(1+\pi) \bar{b}=87.926,30$ e $b_{22}=(1+\pi) \bar{b}=138.252,08$ em milhões de reais.

No modelo com contingenciamento mas sem incentivos, a utilidade para os órgãos, $U_{C}$, é:

$$
U_{C}=\log \left(b_{11}\right)+\log \left(b_{12}\right)+\delta\left(\log \left(b_{21}\right)+\log \left(b_{22}\right)\right)=17,84
$$

O ganho financeiro com o contingenciamento para o governo em milhões de reais é:

15 Dados obtidos pelos sistema SIAFI/STN disponíveis sob demanda aos autores. 


$$
G_{C}=\left[i_{11}+\delta i_{21}(1+\pi)\right]\left[\frac{B}{2}-\bar{b}\right]=4.104,83
$$

No modelo com incentivos, $\bar{\lambda}=\sqrt{\frac{1+\pi}{\delta}\left(1+\frac{1}{\delta} \frac{i_{12}}{1+i_{21}+i_{22}}\right) \frac{\bar{b}}{B-\bar{b}}}=0,9021$. Ou seja, 90,21\% do recurso poupado no primeiro ano deveria ser devolvido aos órgãos. Neste caso, a despesa executada no segundo período do primeiro exercício, em milhões de reais, seria:

$$
b_{12}(\lambda)=118.132,10
$$

Observe que há uma redução de mais de 10 bilhões de reais nos gastos no segundo período. No primeiro período do segundo ano o gasto do órgão será $b_{21}(\lambda)=97.192,39$, um aumento de pouco mais de 9 bilhões com relação à situação sem incentivos.

Assim, o ganho financeiro adicional para o governo seria, em milhões de reais:

$$
G(\lambda)=\left[i_{12}+\delta\left(1+i_{21}+i_{22}\right)(1-\lambda)\right]\left[\frac{\delta}{1+\delta}(B-\bar{b})-\frac{1+\pi}{1+\delta} \frac{\bar{b}}{\lambda}\right]=2.014,81
$$

O ganho total, para o governo, com o mecanismo é de: $G_{C}+G(\lambda)=6.119,64$ milhões de reais. Desta forma, com o novo mecanismo de incentivos o governo teria conseguido uma economia adicional de recursos equivalente a quase $50 \%$ do total economizado com o contingenciamento. Observe que essa economia ocorre apesar do valor de $\lambda$ necessário para estimular a redução de gastos ser muito elevado: $\lambda=90,71 \%$. Um menor valor de $\lambda$, resultado, por exemplo, de uma menor inflação $\pi$, aumentaria consideravelmente o ganho para o governo.

Observe que a utilidade para os órgãos com incentivos seria:

$$
U_{I}=\log \left(b_{11}\right)+\log \left(b_{12}(\lambda)\right)+\delta\left(\log \left(b_{21}(\lambda)\right)+\log \left(b_{22}\right)\right)=17,84=U_{C}
$$


A igualdade obtida resulta do fato de que $\lambda$ é a parcela mínima do valor poupado que deve ser entregue ao órgão, para que ele seja indiferente entre economizar ou não, ou seja, o órgão obtém a mesma utilidade que obteria com contingenciamento e sem incentivos. Este resultado comum nos problemas do tipo Principal-Agente reflete a capacidade de o governo extrair para si todos os ganhos possíveis da prática de contingenciar. No entanto, com um $\lambda$ ligeiramente maior que 0,9071 , poupar torna-se estritamente vantajoso para o órgão.

\section{CONCLUSÃO}

Este trabalho teve por motivação principal a preocupação, predominante no Brasil atual, com o equilíbrio das contas públicas.

Num primeiro momento ressaltou-se que, apesar do Programa de Estabilidade Fiscal (PEF) estar sendo bem-sucedido, subsiste a preocupação com a sustentabilidade do ajuste ao longo do tempo, uma vez que as receitas extraordinárias em que foram baseadas o PEF tendem a desaparecer até 2003. Desta forma, conclui-se que o governo terá que redobrar esforços para diminuir gastos. Para tanto, foi considerado o mecanismo atual de elaboração e execução orçamentária.

A forma como os limites orçamentários são definidos dificulta a diminuição de despesas, já que estes são baseados na execução da despesa nos últimos três anos. Isto faz com que os órgãos gastem todos os recursos disponíveis para evitar cortes em dotações futuras. Por sua vez, os órgãos, com a função de obter os resultados fiscais pretendidos, têm utilizado a repressão fiscal, efetuada pelo contingenciamento de despesas e pelo controle das liberações financeiras pelo Tesouro Nacional, para diminuir despesas. Foi argumentado que esses instrumentos geram uma série de distorções no gasto público.

Nesse contexto, foi então proposto um modelo para o aperfeiçoamento da execução orçamentária e financeira, visando eliminar o comportamento 
incremental dos órgãos, diminuir a necessidade de repressão fiscal e aumentar a eficiência do gasto público. O modelo introduzido neste trabalho mostra-se, a um só tempo, oportuno e relativamente simples. O governo incentiva os órgãos a eliminarem o comportamento incremental e a economizarem recursos com um "prêmio" dado no ano seguinte na forma de uma proporção do valor economizado. A redução de gastos, sendo feita pelo órgão responsável pelos projetos e atividades, pode ser implementada com melhor desempenho e avaliação se comparado ao que ocorre com os cortes efetuados pelo Governo Central. Afinal, são os órgãos que acompanham a execução da despesa mais de perto, tendo maiores condições de avaliar onde os gastos podem ser diminuídos ou não.

Além disso, o governo fica menos estimulado e menos pressionado para recorrer a tantas medidas de corte de despesas e aumento de receitas extraordinárias, que geram inúmeras distorçõos e estão cada vez mais esgotadas. Vale ressaltar que, com a continuação desse mecanismo por períodos maiores que dois anos, o governo pode, aos poucos, ir diminuindo o contingenciamento, já que os próprios órgãos têm motivação para gastar menos e melhor.

O modelo é relativamente simples do ponto de vista técnico, principalmente levando-se em conta que, atualmente, existe a prática de os órgãos utilizarem os recursos que sobram em seus caixas no final de um ano para executar despesas do orçamento do ano seguinte ou então para pagar os "restos a pagar” (despesas liquidadas e não pagas no ano anterior). A realização do prêmio dado pela poupança efetuada seria feita com a criação de condições para que os recursos economizados no ano anterior fossem utilizados para executar despesas não incluídas no orçamento corrente, ou seja, uma espécie de orçamento complementar seria dado aos órgãos poupadores. Esses recursos poderiam ser utilizados com alguma discricionariedade pelo órgão, de forma a otimizar o uso de seus recursos.

Existem, no entanto, pelo menos duas dificuldades a serem vencidas para a implantação de um tal mecanismo. Em primeiro lugar seriam necessárias mudanças na legislação orçamentária. Por exemplo, o uso dos recursos poupados teria que ser autorizado e regulamentado na Lei de Diretrizes Orçamentárias ou na própria Lei Orçamentária Anual, estabelecendo quanto dos recursos e 
de que forma eles poderiam ser gastos. Além disso, deve-se considerar que a informação de quanto foi poupado por cada órgão durante um ano somente estará disponível em janeiro do ano seguinte, quando o orçamento referente a esse ano já tiver sido aprovado. ${ }^{16}$ Portanto, será necessária uma estimativa de quanto será poupado num ano para se ter uma previsão de quanto deverá ser reservado para devolução no ano seguinte. Essas mudanças, por sua vez, deveriam ser aprovadas pelo Poder Legislativo, o que poderia acarretar negociações políticas e, talvez, algumas dificuldades para colocar o modelo em prática. Assim, questões de ordem política tornam-se fundamentais na implementação do mecanismo considerado.

Em segundo lugar, pode existir um problema de credibilidade no que diz respeito ao comportamento dos órgãos de controle de gastos do governo. Com efeito, para que o mecanismo funcione, os órgãos devem ter certeza que a economia atual não será transformada em cortes orçamentários futuros. Caso tenham dúvidas quanto ao comportamento futuro do governo, poderão ter menor incentivo à redução de gastos. Esta é a principal razão pela qual o modelo atual se apresenta como um modelo temporário, uma vez que um compromisso de longo prazo do governo quanto a orçamentos futuros pode ser considerado pouco crível. Uma segunda razão para se enquadrar o mecanismo proposto como temporário refere-se ao fato de que ele atua sobre um incentivo perverso causado justamente pelo uso exagerado do contingenciamento. À medida que o processo orçamentário for se aperfeiçoando, esse uso abusivo irá se reduzindo e os órgãos deixarão de ter incentivo a economizar, uma vez que seus gastos já estarão naturalmente equilibrados ao longo do tempo. Nessa última situação haverá ainda contingenciamento originado pela incerteza quanto à receita efetivamente realizada, conforme reconhecido inclusive pelos defensores do orçamento impositivo ${ }^{17}$; no entanto, o efeito desse contigenciamento sobre o interesse dos órgãos por um esquema de premiação à redução dos gastos deverá ser limitado.

16 Os autores agradecem a um parecerista anônimo por esta observação.

17 Vide, por exemplo, as Propostas de Emenda Constitucionais PEC 9 de 2002 e 22 de 2000 (Senado Federal) e PEC 419 de 2001 (Câmara dos Deputados), todas implantando o orçamento impositivo, mas com possibilidade de contingenciamento. Os autores agradecem a um parecerista anônimo por indagar sobre a relação do presente modelo com o debate sobre orçamento impositivo. 
A análise de um modelo que inclua o risco de não cumprimento, por parte do governo, e explore seus efeitos sobre as decisões dos órgãos, bem como um modelo que considere a redução paulatina do nível de contingenciamento é deixada como proposta para pesquisas futuras.

\section{REFERÊNCIAS BIBLIOGRÁFICAS}

ALÉM, A. C.; GIAMBIAGI, F. O ajuste do governo central: além das reformas. Em: GIAMBIAGI, F, MOREIRA, M. (eds.), A economia brasileira nos anos 90. Rio de Janeiro: BNDES, 1999.

AVERBUG, A.; GIAMBIAGI, F. A crise brasileira de 1998/1999 - Origens e consequências. BNDES Texto para Discussão n. 77, Rio de Janeiro, maio 2000.

BARBOSA, F.; GIAMBIAGI, F. O ajuste fiscal e 1990/93: uma análise retrospectiva. Revista Brasileira de Economia, v. 49, n. 3, jul./set. 1995.

BLANCHARD, O. J.; FISCHER, S. Lectures on macroeconomics. Cambridge: MIT Press.

BRASIL, Ministério do Planejamento e Orçamento, Secretaria de Orçamento Federal. Instruções para elaboração da proposta orçamentária da União para 1999. Manual Técnico de Orçamento (MTO-02), Brasília: IN, 1998.

BRASIL. Secretaria de Política Econômica/MF. Boletim de Acompanhamento Macroeconômico, fev./mar. 2000.

BRASIL. Secretaria do Tesouro Nacional. Resultado do Tesouro Nacional. Brasília, v. .5, n. 12, dez. 1999.

FRANCO, G. A crise fiscal da União: diagnóstico e apontamentos para uma lei das finanças públicas. In: FRANCO. G., O Plano Real e outros ensaios. Rio de Janeiro: Francisco Alves, 1995.

GIAMBIAGI, F. Necessidades de financiamento do setor puiblico: bases para a discussão do ajuste fiscal no Brasil - 1991/1999. Texto para Discussão n. 53, Rio de Janeiro: BNDES, maio 1997.

GIAMBIAGI, F. A crise fiscal da União: o que aconteceu recentemente? Revista de Economia Politica, v. 17, n. 1, p. 60-79, jan./mar. 1997.

GIAMBIAGI, F.; ALÉM, A. C. Finanças públicas: teoria e prática no Brasil. Segunda edição. Rio de Janeiro: Campus, 2001.

GIAMBIAGI, F.; RIGOLON, F. J. Z. O ajuste fiscal de médio prazo: o que vai acontecer quando as receitas extraordinárias acabarem? Texto para Discussão n. 70, Rio de Janeiro: BNDES, ago. 1999. 
GUARDIA, E. R. O processo orçamentário do governo federal: considerações sobre o novo arcabouço institucional e a experiência recente. Texto para Discussão n. 12, São Paulo: Instituto de Economia do Setor Público-IESP, São Paulo, dez. 1993.

HAMILTON, J. D. Time series analysis. Princeton University Press, 1994.

MACKINNON, J. G. Critical values for cointegration tests. Em: ENGLE, R. F; GRANGER, C. W. J., Long-run economic relationships: readings in cointegration. Oxford U. P., 1991.

OURIVES, L. A sustentabilidade da dívida pública na presença de déficit quasi-fiscal. In: Finanças públicas: VII Prêmio Tesouro Nacional. Brasília: Editora UnB, 2003.

REZENDE, F. Finanças públicas. Segunda edição. São Paulo: Atlas, 2001.

RIGOLON, F. J. Z.; GIAMBIAGI, F. A economia brasileira: panorama geral. Série Estudos Econômicos, Rio de Janeiro: BNDES, jun. 1999.

SIGELMANN, D. Resultado fiscal ajustado pelo ciclo: conceito, metodologia e aplicação ao Brasil-1999-2002. 2003. Dissertação (Mestrado), Departamento de Economia, UnB, Brasília.

SIMONSEN, M. H. A inflação brasileira: lições e perspectivas. Revista de Economia Política, v. 5, n. 4, p. 15-30, out./dez. 1985.

TANZI, V. Inflation, lags in collection and the real value of tax revenue. IMF staff Papers, 24, março de 1977.

VELLOSO, R. A situação das contas públicas após o Real. In: VELLOSO, J. P. R. (coord.), O Brasil e o mundo no limiar do novo século. 2v. Rio de Janeiro: José Olympio, 1998.

. Rigidez orçamentária da União. In: VELLOSO, J. P. R. (org.), Brasil: a superação da crise. Brasília: Fórum Nacional as Bases do Desenvolvimento Moderno, 1993. 


\section{APÊEDICE}

Demonstração da Proposição 1

O programa do órgão é dado por:

$$
\left\{\begin{aligned}
& \underset{b_{11}, b_{12}, b_{21}, b_{22}}{\operatorname{Max}} U\left(b_{11}\right)+U\left(b_{12}\right)+\delta\left[U\left(b_{21}\right)+U\left(b_{22}\right)\right] \\
& r . a: b_{11} \leq \bar{b} \\
& b_{11}+b_{12} \leq B \\
& b_{21} \leq(1+\pi) \bar{b}+\lambda\left[B-\left(b_{11}+b_{12}\right)\right] \\
& b_{21}+b_{22} \leq(1+\pi) B+\lambda\left[B-\left(b_{11}+b_{12}\right)\right]
\end{aligned}\right.
$$

Sua solução será derivada em várias etapas.

Etapa 1: Como $U$ é estritamente crescente, e qualquer recurso não gasto no último período é perdido, a restrição (4) é ativa: $b_{22}=(1+\pi) B+\lambda\left[B-\left(b_{11}+b_{12}\right)\right]-b_{21}$.

Etapa 2: Cada real transferido do primeiro para o segundo exercício envolve duas perdas para o órgão; a primeira diz respeito ao fato de que apenas $\lambda$ centavos por real serão devolvidos no exercício seguinte; a segunda referese ao desconto intertemporal $\delta$, ou seja, ao evitar um gasto hoje, o órgão estará transferindo parte desse gasto para o próximo período e essa espera lhe é custosa. Assim, o órgão não terá interesse em transferir recursos do primeiro exercício para ser gasto no segundo período do segundo exercício: todo o recurso poupado no primeiro exercício deverá ser usado no primeiro período do segundo exercício. Mas então (3) também será ativa: $b_{21}=(1+\pi) \bar{b}+\lambda\left[B-\left(b_{11}+b_{12}\right)\right]$.

Etapa 3: Das etapas anteriores conclui-se que $b_{22}=(1+\pi)(B-\bar{b})$. 
Etapa 4: Como o órgão é avesso ao risco, ele tentará reduzir a variação nos gastos no primeiro exercício. Como $\bar{b}<\frac{B}{2}$ e como existem as perdas de recursos poupadas descritas na etapa 2 , a poupança no primeiro exercício nunca envolverá os recursos liberados no primeiro período: $b_{11}=\bar{b}$.

Etapa 5: Dadas as simplificações obtidas nas etapas 1 a 3, o problema original pode ser reescrito como:

$\underset{b_{12}}{\operatorname{Max}} U(\bar{b})+U\left(b_{12}\right)+\delta\left[U\left((1+\pi) \bar{b}+\lambda\left(B-\left(\bar{b}+b_{12}\right)\right)\right)+U((1+\pi)(B-\bar{b}))\right]$

Etapa 6: Como a função $U$ é estritamente côncava, a condição de primeira ordem indicará a solução do problema. Essa condição é:

$U^{\prime}\left(b_{12}\right)=\delta \lambda U^{\prime}\left((1+\pi) \bar{b}+\lambda\left(B-\left(\bar{b}+b_{12}\right)\right)\right)$

O que completa a demonstração da proposição.

Ganho Líquido para o Governo com o Contingenciamento e o Mecanismo de Incentivos

Para calcular as expressóes das funções-objetivo apresentadas no texto deve-se estimar o custo, para o governo federal, com os gastos dos órgãos em cada uma das seguintes situações: sem contingenciamento, com contingenciamento mas sem incentivos, com contigenciamento e com incentivos.

Para tanto, considera-se, no modelo de dois exercícios, que o governo capta todos os recursos necessários a cada período no mercado de títulos públicos, pagando juros referentes à sua dívida acumulada a cada período (taxa SELIC). Supõe-se que a União refinancia toda sua dívida ao final de cada período, exceto no final do segundo período do segundo exercício, quando toda a dívida é paga.

Sejam $b_{k}(n), b_{k}(c), b_{k}(\lambda)$ as soluções respectivas do problema do órgão no período $k$ do exercício $j, j, k=1,2$ quando não há contingenciamento $(n)$, 
quando há contingenciamento, mas não é implementado nenhum mecanismo de incentivos $(c)$, e quando é usado o esquema de incentivos $(\lambda)$. Então o custo total para o governo, correspondente em cada uma dessas situações, é dado pela expressão abaixo, em que $t=n, c, \lambda$ e $i_{j k}$ é a taxa de juros (SELIC) correspondente ao período $k$ do exercício $j, j, k=1,2$.

$C(t)=i_{11} b_{11}(t)+i_{12}\left(b_{11}(t)+b_{12}(t)\right)+\delta i_{21}\left(b_{11}(t)+b_{12}(t)+b_{21}(t)\right)+\delta\left(1+i_{22}\right)\left(b_{11}(t)+b_{12}(t)+b_{21}(t)+b_{22}(t)\right)$

O primeiro termo da soma acima corresponde ao custo de captação do recurso gasto no primeiro período do primeiro exercício: $b_{\mathrm{p}}(t)$. O segundo termo corresponde ao custo de captação do recurso gasto no segundo período do primeiro exercício, $b_{2}(n)$, adicionado ao custo de refinanciamento ("rolagem") da dívida acumulada no período anterior, $b_{\mathfrak{R}}(t)$. Os terceiro e quarto termos envolvem o fator de desconto $\delta$ por se tratarem de custos que serão incorridos no período seguinte. A expressão referente ao primeiro período do segundo exercício é análoga às anteriores. Ao último somando, no entanto, é adicionado o pagamento do estoque da dívida acumulada.

Substituindo os valores encontrados anteriormente, correspondentes às escolhas ótimas do órgão em cada caso $t=n, c, \lambda$., chega-se às seguintes expressões para o custo da União:

Situação 1: Sem Contingenciamento

$$
C(n)=i_{11} \frac{B}{2}+i_{12} B+\delta i_{21}\left(B+(1+\pi) \frac{B}{2}\right)+\delta\left(1+i_{22}\right)(B+(1+\pi) B)
$$

Situação 2: Com Contingenciamento mas sem Incentivos

$$
C(c)=i_{11} \bar{b}+i_{12} B+\delta i_{21}(B+(1+\pi) \bar{b})+\delta\left(1+i_{22}\right)(B+(1+\pi) B)
$$


Situação 3: Com Contingenciamento e com Incentivos

$$
\begin{aligned}
& C(\lambda)=i_{11} \bar{b}+i_{12}\left(\bar{b}+b_{12}\right)+\delta i_{21}\left(\bar{b}+b_{12}+\lambda\left(B-\bar{b}-b_{12}\right)+(1+\pi) \bar{b}\right)+ \\
& +\delta\left(1+i_{22}\right)\left(\bar{b}+b_{12}+\lambda\left(B-\bar{b}-b_{12}+(1+\pi) B\right)\right.
\end{aligned}
$$

Comparando as expressões acima pode-se obter o ganho líquido com o consorciamento e com o mecanismo de incentivos proposto:

Ganho Líquido com o Consorciamento:

$$
G L(c)=C(n)-C(c)=i_{11}\left(\frac{B}{2}-\bar{b}\right)+\delta i_{21}(1+\pi)\left(\frac{B}{2}-\bar{b}\right)
$$

Ganho Liquido Adicional com o Mecanismo de Incentivos:

$$
G L(\lambda)=C(c)-C(\lambda)=\left[i_{12}+\delta\left(1+i_{21}+i_{22}\right)(1-\lambda)\right]\left[B-\bar{b}-b_{12}\right]
$$

Os autores agradecem a Claudiano M. de Albuquerque, Eduardo Guardia, Flávio Versiani, José Carlos de Oliveira e Maria Eduarda T. Pianto pelos comentários e sugestões. Uma versão anterior deste estudo foi premiada no IV Prêmio Tesouro Nacional. Os erros remanescentes são de inteira responsabilidade dos autores. Favor enviar correspondência para Maurício Bugarin.

UnB - ICC Norte, Asa Norte, 60910-900, Brasília, DF, e-mail: bugarin@unb.br. UnB - ICC Norte, Asa Norte, 60910-900, Brasília, DF, e-mail: mirta@unb.br. (Recebido em março de 2003. Aceito para publicação em junho de 2003). 